\title{
New staging system for pulmonary neuroendocrine tumors: A clinical and pathologic necessity
}

Ming-Ching Lee, MD, ${ }^{a}$ Rania G. Aly, MD, PhD, ${ }^{\text {b,c }}$ and Prasad S. Adusumilli, MD, FACS, FCCP ${ }^{\mathrm{b}, \mathrm{d}}$

Central Message
Although neuroendocrine tumors are rare, their incidence has been increasing in recent years. ${ }^{1}$ Pulmonary neuroendocrine tumors (PNETs) consist of a heterogenous group of tumors-typical carcinoid (TC), atypical carcinoid, large cell neuroendocrine carcinoma, and small cell carcinoma-that share morphologic, molecular, and immunohistochemical characteristics. ${ }^{2}$ These tumors are graded according to mitotic activity, presence of necrosis, and Ki-67 proliferation index. Survival analysis has shown that large cell neuroendocrine carcinoma and small cell carcinoma exhibit the worst survival, whereas TC has the best. $^{3}$ The importance of PNET grading is highlighted by its inclusion in the National Comprehensive Cancer Network guidelines for patient management. ${ }^{4}$ The TNM staging system used for PNETs is the same as for non-small cell lung cancer (NSCLC). ${ }^{5}$ Although this approach is convenient, the staging of PNETs may benefit from more specific criteria because their pathologic and clinical outcomes are highly variable among different subtypes when compared with NSCLC.

To this end, Cattoni and colleagues ${ }^{6}$ analyzed clinical and pathologic data from 510 cases of resected primary grade 1 (G1) TC, grade 2 (G2) atypical carcinoid, and grade 3 (G3) large cell neuroendocrine carcinoma from 8 centers and their results are presented in this issue of the Journal. Cattoni and colleagues ${ }^{6}$ compared disease-free survival (DFS) with either a modified staging system or the seventh edition TNM staging system for NSCLC. In applying their proposed staging system-IA (pT1-2G1), IB (pT3G1, pT1G2), IIA (pT4G1, pT2-3G2, pT1G3), IIB (pT4G2, pT2-3G3), and III (pT4G3) — Cattoni and colleagues ${ }^{6}$ found a clear difference in 5-year DFS $(98 \%, 81 \%, 69 \%, 52 \%$, and $0 \%$, respectively) compared with stratification according to the seventh edition TNM staging system (5-year DFS

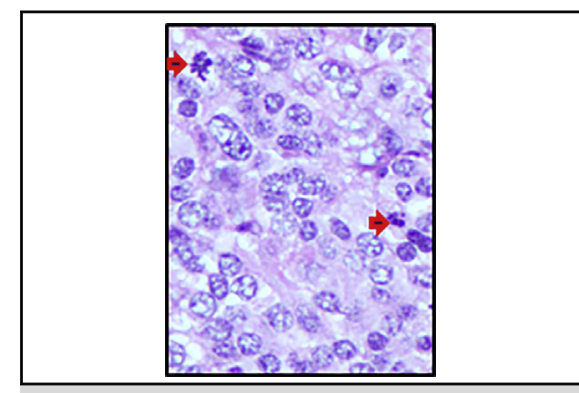

Hematoxylin and eosin staining $(\times 400)$ of atypical carcinoid demonstrating mitoses (arrow).

A modified staging system that incorporates tumor grades may be beneficial for pulmonary neuroendocrine tumors.

See Article page 405.

$95 \%, 92 \%, 68 \%, 71 \%$, and $65 \%$ for stages IA, IB, IIA IIB, and III, respectively).

This study by Cattoni and colleagues ${ }^{6}$ is relevant and important because it includes a large, multi-institutional cohort. They evaluated DFS, which is a better statistical metric for cancer-related deaths than overall survival and reflects tumor biology. ${ }^{7}$ Furthermore, the proposed staging system is practical and simpler to reproduce.

However, this study does have several limitations. The study design was retrospective, the inclusion criteria may hamper generalizability, and, despite the large cohort, $67 \%$ of the cases were TC, which already have a good prognosis. ${ }^{8,9}$ Furthermore, the inclusion of cases without lymph node sampling or dissection may explain why lymph node metastasis was not found to be a statistically significant contributing factor. Additionally, the distribution of surgical procedures (wedge $15 \%$ vs anatomic $77 \%$ ) indicates that procedure choice may also be a relevant factor. The absence of a central pathologist and the lack of a second review of histologic slides limit the validity of the pathologic data.

Despite these limitations, Cattoni and colleagues ${ }^{6}$ should be commended for their multi-institutional efforts to address this clinical necessity. The proposed staging system provides a platform for future studies, with a study design that incorporates clinical and pathologic variables, including predetermined pathologic criteria, and a comparison of outcomes with the eighth edition of the TNM classification system. 
We thank Alex Torres of the MSK Thoracic Surgery Service for his editorial assistance.

\section{References}

1. Yao JC, Hassan M, Phan A, Dagohoy C, Leary C, Mares JE, et al. One hundred years after "carcinoid": epidemiology of and prognostic factors for neuroendocrine tumors in 35,825 cases in the United States. J Clin Oncol. 2008;26: 3063-72.

2. Travis WD, Brambilla E, Nicholson AG, Yatabe Y, Austin JHM, Beasley MB, et al. The 2015 World Health Organization classification of lung tumors: impact of genetic, clinical and radiologic advances since the 2004 classification. J Thorac Oncol. 2015;10:1243-60.

3. Travis WD, Rush W, Flieder DB, Falk R, Fleming MV, Gal AA, et al. Survival analysis of 200 pulmonary neuroendocrine tumors with clarification of criteria for atypical carcinoid and its separation from typical carcinoid. Am J Surg Pathol. 1998;22:934-44.

4. National Comprehensive Cancer Network. NCCN Clinical Practice Guidelines in Oncology (NCCN guidelines): Small Cell Lung Cancer. Version 1.2017. Fort Washington (PA): National Comprehensive Cancer Network; 2016. Available at: https://www.nccn.org/professionals/physician_gls/f_guidelines.asp. Accessed October 12, 2017.

5. Edge SB, Compton CC. The American Joint Committee on Cancer: the 7th edition of the AJCC cancer staging manual and the future of TNM. Ann Surg Oncol. 2010; 17:1471-4.

6. Cattoni M, Vallières E, Brown LM, Sarkeshik AA, Margaritora S, Siciliani A, et al. Improvement in TNM staging of pulmonary neuroendocrine tumors requires histology and regrouping of tumor size. J Thorac Cardiovasc Surg. 2018;155:405-13.

7. Eguchi T, Kadota K, Park BJ, Travis WD, Jones DR, Adusumilli PS. The new IASLC-ATS-ERS lung adenocarcinoma classification: what the surgeon should know. Semin Thorac Cardiovasc Surg. 2014;26:210-22.

8. Caplin ME, Baudin E, Ferolla P, Filosso P, Garcia-Yuste M, Lim E, et al; ENETS consensus conference participants. Pulmonary neuroendocrine (carcinoid) tumors: European Neuroendocrine Tumor Society expert consensus and recommendations for best practice for typical and atypical pulmonary carcinoids. Ann Oncol. 2015;26: 1604-20.

9. Filosso PL, Ferolla P, Guerrera F, Ruffini E, Travis WD, Rossi G, et al; European Society of Thoracic Surgeons Lung Neuroendocrine Tumors Working-Group Steering Committee. Multidisciplinary management of advanced lung neuroendocrine tumors. J Thorac Dis. 2015;7(Suppl 2):S163-71. 